\title{
Development of rice growth map using the advanced remote sensing techniques
}

\begin{abstract}
Rice monitoring is one of the main issues in rice productivity. Farmers face difficulties in monitoring their rice fields due to climate change, soil conditions, age of the farmers and time consumed to monitor the whole area. Remote sensing technology is one of the alternatives to monitor rice field. The advancement of unmanned aerial vehicle (UAV) technology has been rapidly growing and frequently used in the agriculture industries to monitor crop condition. The objectives of this research are creating crop growth map using aerial imagery and objectbased image analysis (OBIA) technique, and validating the normalized difference vegetative index (NDVI) value in rice field map using soil plant analysis development (SPAD) and GreenSeeker data. The multispectral image is processed using OBIA to produce crop growth map. The crop growth map produced is embedded with information that is able to indicate the health status of the rice crop using NDVI. This research was carried out at a paddy field planted using PadiU Putra variety in Ladang Merdeka, Ketereh, Kelantan (0.79 ha). The results from this research show that OBIA method can classify vegetation and non-vegetation to produce crop growth map. NDVI map has a strong correlation with Greenseeker data at 0.893 with positive correlation at 0.05 compared to SPAD meter. The crop growth map allows farmers to improve their rice farm monitoring more effectively using remote sensing technique.
\end{abstract}

Keyword: Rice mapping; UAV; Multispectral sensor 